\title{
Implementasi Komunikasi Daring dalam Menunjang Jawa Barat sebagai Destinasi Pariwisata Cerdas
}

\author{
Evi Novianti, Shandra Rama Panji Wulung \\ Universitas Padjadjaran, Jl. Dipatiukur No.35, Bandung 40132, Jl. Raya Bandung Sumedang KM \\ 21, Jatinangor, Sumedang 45363, dan Universitas Pendidikan Indonesia, J1. Setiabudhi No. 229, \\ Bandung 40154 \\ evi.novianti@unpad.ac.id; wulung@upi.edu
}

Masuk tanggal : 16-05-2019, revisi tanggal : 10-03-2020, diterima untuk diterbitkan tanggal : 16-03-2020

\begin{abstract}
Tourism communication currently tends to be online-based and refers to tourist behavior preferences. West Java as a tourism destination has a variety of online-based tourism communication. This study aims to identify the efforts of the Tourism and Culture Office of West Java in realizing West Java as a smart tourism destination through online communication and the Smiling West Java mobile application. The qualitative method is the approach in this study with primary and secondary data collection. The unit of analysis in this research covers the function of online communication media utilities and components of tourism destinations. This study uses qualitative analysis methods and content analysis methods and is complemented by descriptive qualitative analysis methods through data analysis before going to the field, data reduction, data presentation, and concluding. The efforts of the Tourism and Culture Office of West Java in communicating tourism through three main online media namely websites, social media, and mobile applications. Smiling West Java is a manifestation of smart tourism destinations owned by West Java and provides global scale competitiveness.
\end{abstract}

Keywords: smiling west java, smart tourism destination, tourism communication, West Java

\begin{abstract}
Abstrak
Komunikasi pariwisata saat ini cenderung berbasis daring dan mengacu kepada preferensi perilaku wisatawan. Jawa Barat sebagai destinasi pariwisata memiliki berbagai komunikasi pariwisata berbasis daring. Penelitian ini bertujuan untuk mengidentifikasi upaya Dinas Pariwisata dan Kebudayaan Provinsi Jawa Barat dalam mewujudkan Jawa Barat sebagai destinasi pariwisata cerdas melalui komunikasi daring dan aplikasi seluler Smiling West Java. Metode kualitatif menjadi pendekatan pada penelitian ini dengan pengumpulan data data primer dan sekunder. Unit analisis dalam penelitian mencakup fungsi utilitas media komunikasi daring dan komponen destinasi pariwisata. Penelitian ini menggunakan metode analisis kualitatif dan metode analisis isi dan dilengkap dengan metode analisis deskriptif kualitatif melalui analisis data sebelum ke lapangan, reduksi data, penyajian data, dan penarikan kesimpulan. Upaya Pemerintah Provinsi Jawa Barat melalui Dinas Pariwisata dan Kebudayaan dalam mengkomunikasikan pariwisata melalui tiga media daring utama yaitu situs web, media sosial, dan aplikasi seluler. Smiling West
\end{abstract}


Java menjadi manifestasi destinasi pariwisata cerdas yang dimiliki oleh Jawa Barat dan memberikan daya saing skala global.

Kata Kunci: destinasi pariwisata cerdas, komunikasi pariwisata, Jawa Barat, smiling west java

\section{Pendahuluan}

Destinasi pariwisata menghadapi berbagai tantangan baru yang timbul dari perubahan perilaku wisatawan dan lingkungan fisik yang dipengaruhi oleh teknologi informasi dan komunikasi (Boes et al., 2016; Buhalis \& Amaranggana, 2013, 2015). Destinasi pariwisata membutuhkan informasi dan komunikasi yang efektif dan efisien dalam upaya meningkatkan daya saing destinasi lebih atraktif (Lee \& Huang, 2014) dan membantu meningkatkan kesadaran wisatawan terhadap destinasi pariwisata (Tunjungsari et al., 2019). Teknologi informasi dan komunikasi dapat berkontribusi dalam menghasilkan nilai tambah berupa pengalaman bagi wisatawan, meningkatkan efisiensi komunikasi, dan mendukung otomatisasi pengelolaan kepariwisataan (Gretzel, 2011; Gretzel et al., 2015). Wisatawan cenderung menyukai informasi yang mereka butuhkan melalui komunikasi daring dibandingkan menggunakan jasa agen perjalanan wisata (Xiang \& Gretzel, 2010). Adanya peningkatan secara signifikan terkait penggunaan media digital sebagai sumber daya informasi dan platform komunikasi oleh wisatawan sebelum melakukan kunjungan ke destinasi pariwisata (Divinagracia et al., 2012). Hal tersebut termasuk penyediaan informasi dan komunikasi daring yang dapat dengan mudah diakses melalui situs, surat elektronik, iklan web, blog, jejaring sosial, dan aplikasi seluler. Lebih lanjut, berbagai sumber informasi dan komunikasi tradisional (koran, buku, majalah, radio, dan televisi) saat ini mulai berkolaborasi dan berinovasi menuju media komunikasi berbasis daring.

Penggunaan teknologi informasi dan komunikasi pariwisata melalui media digital di Jawa Barat sudah ada sejak satu dekade terakhir dengan adanya situs resmi Dinas Pariwisata dan Kebudayaan Provinsi Jawa Barat dan berbagai platform media sosial (Anisa \& Rachmaniar, 2019; Naibaho \& Yusrizal, 2017; Nurfalah \& Wihayati, 2016). Pentingnya aspek komunikasi daring mendorong pemerintah Provinsi Jawa Barat meluncurkan aplikasi seluler berbasis daring yang bernama Smiling West Java. Jauh sebelum diperkenalkannya aplikasi seluler Smiling West Java, terdapat salah satu aplikasi seluler berbasis daring terkait pariwisata di Jawa Barat yaitu Sampurasun Pariwisata Purwakarta (Atthahara, 2018; Novianti et al., 2019). Sampurasun Pariwisata Purwakarta menjadi saran informasi dan komunikasi di Kabupaten Purwakarta dan menjadikannya sebagai salah satu contoh aplikasi destinasi pariwisata pintar (Gustini et al., 2018; Rachmayanti \& Nofharina, 2018).

Terdapat beberapa peneliti sebelumnya yang mengkaji terkait destinasi pariwisata cerdas di berbagai wilayah, diantaranya Divinagracia et al., (2012) yang mengkaji komunikasi daring yang memicu aktivitas pariwisata berbasis alam di Jawa Timur; Koo et al., (2013) mengkaji implementasi pariwisata cerdas yang dilakukan oleh Pemerintah Korea Selatan; Wang et al., (2013) yang mengkaji 
Evi Novianti, Shandra Rama Panji Wulung: Implementasi Komunikasi Daring dalam Menunjang Jawa Barat sebagai Destinasi Pariwisata Cerdas

inisiatif Pemerintah China dalam mengembangkan destinasi pariwisata cerdas; Divya, (2016) mengkaji komunikasi pariwisata berbasis aplikasi selular dari berbagai negara diantaranya aplikasi selular California Travel Guide withMe, Tourism Thailand, Visit Portugal Travel Guide, Australia Tourism, South Afrika Travel Guide, hingga Russia Guide WithMe; Atthahara (2018); Gustini et al. (2018); Novianti et al. (2019) yang mengkaji komunikasi pariwisata Pemerintah Kabupaten Purwakarta melalui aplikasi seluler Sampurasun Pariwisata Purwakarta; Tunggala \& Saadjad (2019) mengkaji strategi komunikasi digital yang dilakukan oleh Dinas Pariwisata dalam memasarkan daya tarik wisata di Kabupaten Banggai, Provinsi Sulawesi Tengah; (Panuju \& Narena, 2019) memaparkan bahwa rekomendasi dan hasil ulasan secara daring merupakan bentuk komunikasi digital yang berpengaruh terhadap kunjungan wisatawan ke Provinsi Bali; dan Setyanto \& Winduwati (2017) yang mengkaji diseminasi informasi pariwisata melalui website dalam meningkatkan daya tarik wisata berwawasan lingkungan dan budaya di Provinsi Nusa Tenggara Barat. Destinasi pariwisata cerdas membutuhkan peran pemangku kepantingan yang saling terintegrasi secara dinamis melalui berbagai platform teknologi informasi dan komunikasi yang berkaitan dengan aktivitas pariwisata (Buhalis \& Amaranggana, 2015). Terdapat tiga bentuk teknologi informasi dan komunikasi yang diperlukan untuk mendukung destinasi pariwisata cerdas, yaitu cloud computing, internet of things (IoT), dan end-user internet service system (Wang et al., 2013).

Destinasi pariwisata dibangun berdasarkan enam variabel utama yang mencakup 1) atraksi atau daya tarik wisata (alam, buatan, dan budaya); 2) aksesibilitas (sistem transportasi yang terdiri dari rute, terminal dan moda transportasi); 3) aminitas mencakup akomodasi dan fasilitas pariwisata yang diperuntukan bagi wisatawan; 4) ketersediaan paket wisata (paket yang diatur sebelumnya oleh pengelola destinasi pariwisata) 5) aktivitas merupakan semua kegiatan tersedia di tujuan dan apa yang akan dilakukan wisatawan selama kunjungan; dan 6) layanan tambahan, layanan yang digunakan oleh wisatawan (seperti bank, telekomunikasi, pos , agen koran, rumah sakit, dll.) (Buhalis, 2000). Adanya perilaku wisatawan yang terus meningkat seiiring dengan perkembangan jaman, metode informasi dan komunikasi pintar antar pemangku kepentingan di destinasi sangat diperlukan dengan tujuan meningkatkan daya saing destinasi parwisiata (Neuhofer et al., 2012).

Destinasi pariwisata cerdas memiliki fungsi utilitas terkait komunikasi daring yang mencakup interpretasi, perencanaan, keberlanjutan, pemanduan, kemudahan, dan umpan balik (Buhalis \& Amaranggana, 2013). Fungsi utilitas tersebut memiliki implementasi yang berbeda-beda dalam menunjang destinasi pariwsiata cerdas. Fungsi interpretasi dapat diimplementasikan pada augmented reality (AR) yang memungkinkan wisatawan untuk mendapatkan pengalaman melalui media digital seperti situs, aplikasi seluler, dan media sosial. Perencanaan diimplementasikan melalui sistem pelacakan kendaraan berbasis waktu yang sebenarnya terkait jaringan transportasi dan dapat digunakan oleh wisatawan sebagai pengguna akhir. Implementasi keberlanjutan pada destinasi pariwisata berkelanjutan terlihat pada penghematan penggunaan energi oleh fasilitas untuk wisatawan seperti hotel. Pemanduan wisata diimplementasikan dalam bentuk 
multilingalisme media berbasis daring, seperti e-brosur, e-flyer, dan e-book terkait pemanduan selama di destinasi. Kemudahan mengakses informasi menggunakan perangkat selular, seperti kode QR dan situs. Yang terakhir yaitu umpan balik dari wisatawan selama dan setelah aktivitas wisata yang dilakukan di destinasi.

Tujuan penelitian ini adalah untuk mengidentifikasi komunikasi daring yang dilakukan oleh Dinas Pariwisata dan Kebudayaan Provinsi Jawa Barat melalui media daring, di samping itu dianalisis juga implementasi dari aplikasi seluler Smiling West Java dalam mengembangkan Jawa Barat sebagai destinasi pariwisata cerdas.

\section{Metode Penelitian}

Metode kualitatif menjadi pendekatan pada penelitian ini dengan jenis data primer dan sekunder. Data primer diperoleh melalui wawancara pada nara sumber yang melakukan aktivitas komunikasi pariwisata berbasis daring, yaitu Bidang Pemasaran Dinas Pariwisata dan Kebudayaan Provinsi Jawa Barat. Sementara data sekunder diperoleh melalui studi pustaka dan penelitian terdahulu terkait komunikasi daring dan destinasi pariwisata cerdas. Unit analisis dalam penelitian mencakup fungsi utilitas media komunikasi daring (interpretasi, perencanaan, keberlanjutan, pemanduan, kemudahan, dan umpan balik) dan komponen destinasi pariwisata (atraksi, aksesibilitas, aminitas, dan ketersediaan paket wisata).

Penelitian ini menggunakan metode analisis kualitatif deskriptif terhadap literasi yang didapatkan melalui observasi lapangan dan wawancara. Penelitian ini juga dilengkapi dengan analisis isi terhadap kebijakan terkait komunikasi pariwisata pada dokumen Rencana Induk Pembangunan Kepariwisataan (Ripparprov) Jawa Barat 2015-2025. Data dan informasi yang didapatkan kemudian dilakukan perbandingan dan diuji pada konsep dan teori yang ada menggunakan prosedur analisis kualitatif melalui analisis data sebelum ke lapangan, reduksi data, penyajian data, dan penarikan kesimpulan.

\section{Hasil Penemuan dan Diskusi}

\section{Komunikasi Daring Pariwisata Jawa Barat}

Komunikasi pariwisata melalui media daring di Jawa Barat mengadaptasi dari visi dan misi pariwisata juara Jawa Barat, yaitu menjadikan pariwisata Jawa Barat sebagai alternatif pilihan kunjungan wisatwan yang unggul dan inovatif di Indonesia melalui pengembangan destinasi pariwisata yang unggul, kelembagaan dan industri pariwisata yang kuat, pemasaran pariwsiata yang inovatif, dan meningkatkan kesejahteraan masyarakat dan wisatawan yang berkunjung ke Jawa Barat. Perwilayahan destinasi pariwisata di Jawa Barat di bagi menjadi lima destinasi, tiga diantaranya dijadikan sebagai destinasi geowisata atau geopark (Rencana Induk Pembangunan Kepariwisataan Provinsi Jawa Barat, 2015; Wulung, 2018). Masing-masing destinasi tersebut memiliki keunggulannya masing-masing, seperti destinasi pariwisata Karawang-Bekasi yang difokuskan 
Evi Novianti, Shandra Rama Panji Wulung: Implementasi Komunikasi Daring dalam Menunjang Jawa Barat sebagai Destinasi Pariwisata Cerdas

sebagai pariwisata industri dan Destinasi Pariwisata Cekungan Bandung yang difokuskan sebagai pariwisata perkotaan.

Terdapat tiga media daring dalam mengkomunikasikan kepariwisataan di Jawa Barat (Gambar 1), yaitu melalui situs, media sosial, dan aplikasi seluler. Situs yang dikelola oleh Dinas Pariwisata dan Kabudayaan Jawa Barat dapat diakses melalui halaman http://www.disparbud.jabarprov.go.id/. Halaman situs tersebut mengkomunikasikan terkait profil kelembagaan kepariwisataan Jawa Barat, berita dan perhelatan terkini, peta wisata, informasi wisata, dan halaman pengaduan. Fungsi utilitas yang dimiliki oleh situs tersebut mencakup 1) interpretasi yang menyajikan informasi, baik lembaga maupun destinasi, yang tertera pada konten pilihan menu; 2) perencanaan melalui peta wisata yang menunjukan titik awal wisatawan menuju destinasi atau daya tarik wisata yang akan dikunjungi; 3) pemanduan wisata melalui rute-rute wisata dan memiliki berbagai bahasa pengantar yaitu Bahasa Indonesia, Inggris, dan Jepang (Gambar 2); 4) umpan balik, situs Dinas Pariwisata dan Kebudayaan Jawa Barat memiliki halaman pengaduan yang memudahkan wisatawan dan masyarakat Jawa Barat dalam melaporkan dan mengadukan terkait aktivitas pariwisata di Jawa Barat.

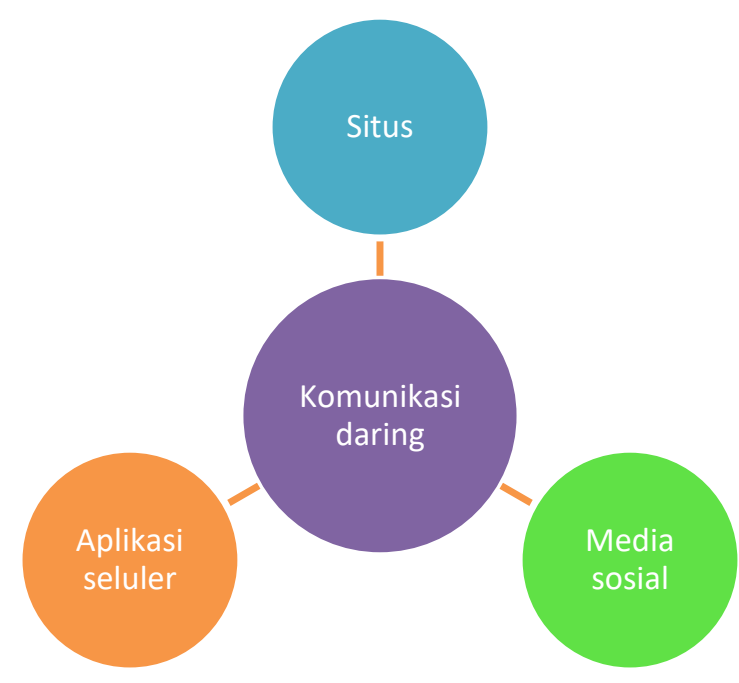

Gambar 1: Komunikasi pariwisata melalui media daring di Jawa Barat

Komunikasi pariwisata melalui media sosial yang dikelola Dinas
Pariwisata dan Kebudayaan Jawa Barat mencakup Twitter
(twitter.com/disparbud_jabar), Facebook (facebook.com/parbudjabar), Youtube
(youtube.com/ channel/UC0aVhPHJxTSTfN8_2jrqiNQ), dan Instagram
(instagram.com/ pesonajawabaratku). Fungsi utilitas yang dari media sosial
sebagai komunikasi pariwisata Jawa Barat mencakup interpretasi (informasi
tentang perhelatan dan daya tarik wisata di jawa barat), pemanduan (membahas
panduan wisata pada setiap destinasi dan daya tarik wisata di Jawa Barat),
kemudahan (dalam bentuk aplikasi yang mudah didapatkan dan diakses melalui


komputer dan seluler), dan umpan balik (media sosial memberikan akses bagi wisatawan dan masyarakat setempat melalui fitur komen dan pesan langsung).
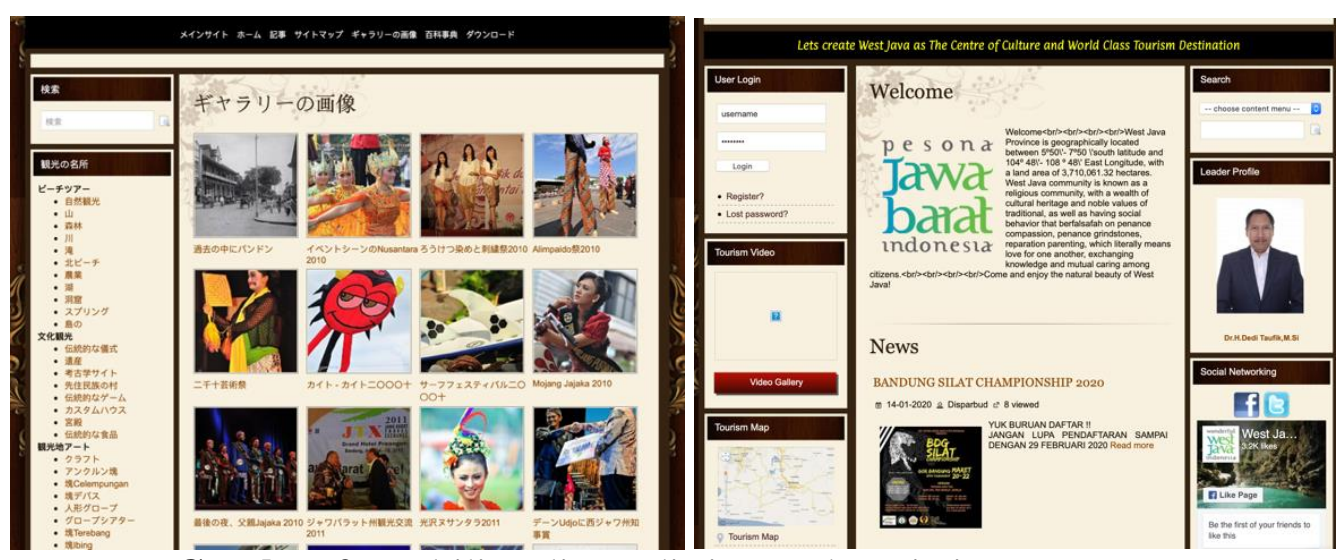

Gambar 2:Multilingalisme di situs web pariwisata Jawa Barat

(Sumber: http://www.disparbud.jabarprov.go.id/, 2019)

Aplikasi selular sebagai komunikasi pariwisata Jawa Barat yaitu Smiling West Java. Aplikasi ini memberikan berbagai konten terkait destinasi dan daya tarik wisata di Jawa Barat (interpretasi), terdapat fitur pemesanan daring paket wisata (perencanaan), mengulas berbagai aktivitas dan fasilitas yang berkelanjutan (berkelanjutan), adanya rute-rute wisata yang disertai dengan $e$ brosur, e-flyer, dan peta wisata (pemanduan), terdapat fitur memindai kode QR (kemudahan), dan fitur kontak pengelola aplikasi memudahkan wisatawan dalam mengajukan pengaduan dan pertanyaan terkait konten-konten yang terdapat di aplikasi Smiling West Java. Secara detail fungsi utilitas komunikasi pariwisata di Jawa Barat dapat dilihat pada Tabel 1.

Tabel 1. Fungsi utilitas komunikasi pariwisata Jawa Barat melalui media daring

\begin{tabular}{lccc}
\hline \multicolumn{1}{c}{ Komunikasi } & \multicolumn{3}{c}{ Media daring } \\
\cline { 2 - 4 } pariwisata & Situs & Media sosial & Aplikasi seluler \\
Interpretasi & $\sqrt{ }$ & $\sqrt{ }$ & $\sqrt{ }$ \\
Perencanaan & $\sqrt{ }$ & - & $\sqrt{ }$ \\
Keberlajutan & - & - & $\sqrt{ }$ \\
Pemanduan & $\sqrt{ }$ & $\sqrt{ }$ & $\sqrt{ }$ \\
Kemudahan & - & $\sqrt{ }$ & $\sqrt{ }$ \\
Umpan Balik & $\sqrt{ }$ & $\sqrt{ }$ & \\
\hline
\end{tabular}

\section{Implementasi Destinasi Pariwisata Cerdas: Aplikasi Smiling West Java}

Pemerintah Provinsi Jawa Barat, melalui Dinas Pariwisata dan Kebudayaan, secara resmi memperkenalkan aplikasi seluler Smiling West Java pada tanggal 2 November 2019 yang bertepatan dengan perhelatan West Java Festival. Tujuan utama hadirnya Smiling West Java yaitu sebagai portal pariwisata, kebudayaan, kuliner Jawa Barat untuk masyarakat Jawa Barat dan wisatawan yang akan berkunjung ke Jawa Barat. Terdapat enam fitur utama yang dimiliki oleh Smiling West Java (Gambar 3), mencakup 1) objek wisata, pencarian keanekaragaman daya tarik wisata dengan berdasarkan kategori dan lokasi; 2) 
Evi Novianti, Shandra Rama Panji Wulung: Implementasi Komunikasi Daring dalam Menunjang Jawa Barat sebagai Destinasi Pariwisata Cerdas

akomodasi, pencarian beragam akomodasi yang tersebar di seluruh Jawa Barat; 3) kuliner, berbagai selera masakan di seluruh Jawa Barat dapat dengan mudah didapatkan informasinya; 4) event, berbagai pehelatan yang akan datang dengan mudah dilakukan pencarian berdasarkan kategori dan lokasinya; 5) transportasi, pencarian berbagai moda transportasi selama wisatawan berada di Jawa Barat; dan 6) oleh-oleh, beragam souvenir yang dapat ditemukan berdasarkan kategori dan lokasi di Jawa Barat.

Implementasi destinasi pariwisata cerdas dapat terlihat dari berbagai fitur yang ditawarkan dalam aplikasi seluler Smiling West Java berdasarkan enam aspek destinasi pariwisata. Aspek pertama yaitu atraksi atau daya tarik wisata dalam Smiling West Java menjadi unsur interpretasi dalam komunikasi daring melalui penyediaan informasi tentang daya tarik wisata yang diklasifikasikan berdasarkan wisata alam, budaya, dan buatan yang tersebar di seluruh Jawa Barat. Aspek aksesibilitas dapat terlihat pada fitur transportasi menjadi implementasi yang menyediakan rute perjalanan dan moda transportasi. Selain itu terdapat juga di fitur lainnya yang menyertakan peta lokasi diantaranya fitur objek wisata, akomodasi, dan kuliner. Aspek ini menjadi fungsi utilitas dari perencanaan pada komunikasi daring.

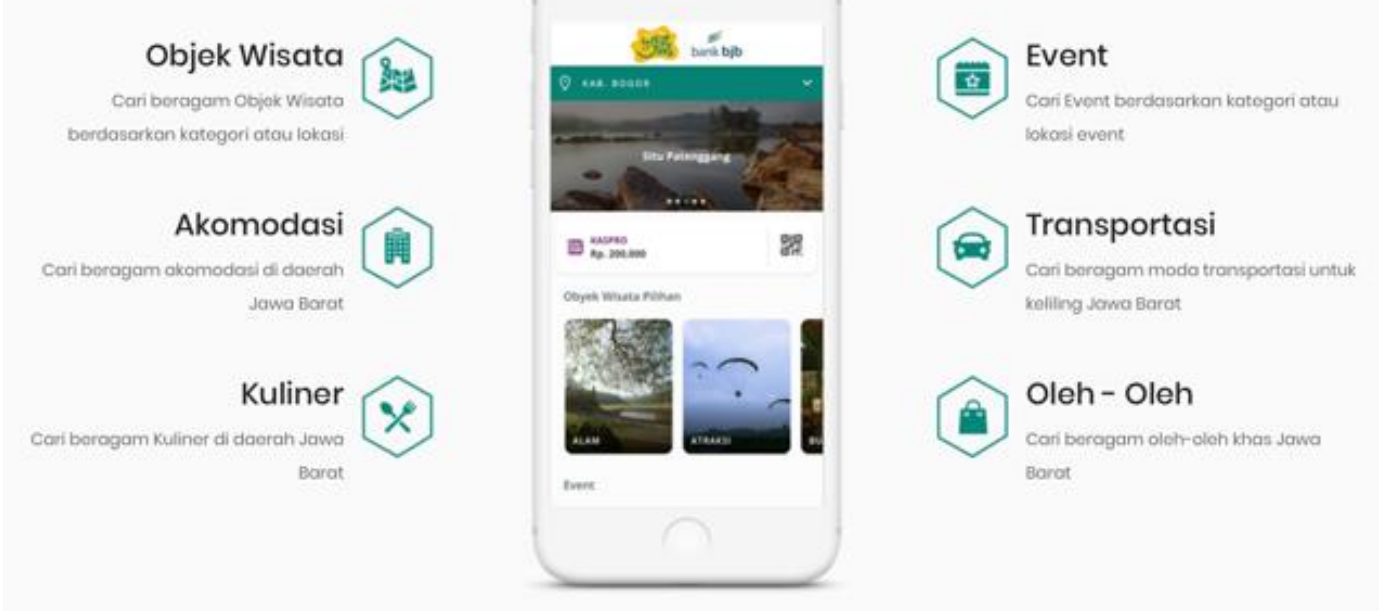

Gambar 3:Enam fitur utama dalam aplikasi seluler Smiling West Java (Sumber: https://smilingwestjava.com/, 2019)

Aspek ketiga yaitu aminitas diimplementasikan dalam fitur akomodasi dan kuliner di aplikasi seluler Smiling West Java. Pada aspek ini diinformasikan terkait hotel yang ramah lingkungan dan mendukung mempromosikan masakan cita rasa Jawa Barat, hal tersebut menjadi fungsi utilitas keberlanjutan. Aspek selanjutnya yaitu aspak ketersediaan paket wisata menjadi fungsi utilitas pemanduan wisata pada komunikasi daring diimplementasikan pada fitur objek wisata dan event. Fitur-fitur tersebut menyediakan paket wisata yang dapat dipesan oleh wisatawan melalui aplikasi seluler Smiling West Java. 
Aspek kelima yaitu aktivitas dapat dilihat pada fitur event dan menjadi. Perhelatan yang berada di Jawa Barat diinformasikan pada fitur event, hal tersebut memudahkan bagi wisatawan dan masyarakat setempat dalam merencanakan perjalanan wisata di Jawa Barat. Aspek terakhir yaitu layanan tambahan dapat terlihat pada fitur oleh-oleh. Berbagai informasi terkait souvenir khas Jawa Barat menjadi konten pada fitur ini, selain itu terdapat peta lokasi yang memudahkan wisatwan untuk mengunjungi tempat oleh-oleh.

Tabel 2. Implementasi destinasi pariwisata cerdas pada aplikasi seluler Smiling West Java

\begin{tabular}{|c|c|}
\hline Aspek Destinasi & Implementasi \\
\hline Atraksi & $\begin{array}{l}\text { Fitur pencarian daya tarik wisata (objek wisata) yang } \\
\text { diklasifikasikan berdasarakan jenis wisata berbasis alam, } \\
\text { budaya, dan buatan. }\end{array}$ \\
\hline Aksesibilitas & $\begin{array}{l}\text { Transportasi menjadi implementasi dari aksesibilitas pada } \\
\text { aplikasi ini yang menyediakan rute perjalanan dan moda } \\
\text { transportasi. }\end{array}$ \\
\hline Aminitas & $\begin{array}{l}\text { Fitur akomodasi menjadi dan kuliner menjadi implementasi } \\
\text { aminitas pada aplikasi ini dengan menyediakan infomasi dan } \\
\text { lokasi di seluruh Jawa Barat. }\end{array}$ \\
\hline $\begin{array}{l}\text { Ketersediaan Paket } \\
\text { Wisata }\end{array}$ & $\begin{array}{l}\text { Fitur objek wisata dan event menawarkan pilihan paket yang } \\
\text { tersedia di Jawa Barat dan dapat dipilih oleh wisatawan. }\end{array}$ \\
\hline Aktivitas & $\begin{array}{l}\text { Event menjadi fitur yang menawarkan pilihan bagi wisatawan } \\
\text { dengan berbagai aktivitas yang dapat dilakukan wisatawan } \\
\text { selema berada di Jawa Barat }\end{array}$ \\
\hline Layanan tambahan & $\begin{array}{l}\text { Oleh-oleh menjadi fitur tambahan pada aplikasi selular ini } \\
\text { dengan menawarkan souvenir khas di seluruh Jawa Barat }\end{array}$ \\
\hline
\end{tabular}

\section{Simpulan}

Provinsi Jawa Barat sebagai destinasi pariwisata cerdas didukung dengan berbagai komunikasi pariwisata melalui media daring yang mencakup situs, media sosial, dan aplikasi seluler. Upaya tersebut memicu Jawa Barat sebagai destinasi pariwisata cerdas yang berdaya saing global. Penyediaan media komunikasi daring di Jawa Barat sebagai upaya untuk lebih mengenalkan keragaman daya tarik wisata, budaya, dan kuliner yang berada di seluruh Provinsi Jawa Barat. Aplikasi membutuhkan pengembangan secara berkala dalam memperbaiki performa dan informasi terkini, hal tersebut menjadi peluang terciptanya kerja sama dengan pihak swasta. Saran praktis tersebut sebagai upaya memperkuat jaringan destinasi pariwisata digital dan memperluas pangsa pasar wisatawan. Penelitian ini juga memiliki kontribusi pada khasanah ilmu pengetahuan, khususnya pada bidang komunikasi pariwisata daring dengan kajian model pariwisata cerdas melalui implementasi komunikasi daring dalam menciptakan destinasi pariwisata yang berdaya saing tinggi dan berkelanjutan. 


\section{Ucapan Terima Kasih}

Tim penulis menyampaikan ucapan terima kasih kepada Bidang Pemasaran dan Bidang Desatinasi Dinas Pariwisata dan Kebudayaan Provinsi Jawa Barat yang telah memberikan dukungan dan kontribusinya pada penelitian ini.

\section{Daftar Pustaka}

Anisa, R., \& Rachmaniar, R. (2019). Media Informasi dan Komunikasi Pemerintah Provinsi Jawa Barat. Jurnal Lontar, 7(1), 36-40.

Atthahara, H. (2018). INOVASI PELAYANAN PUBLIK BERBASIS EGOVERNMENT : STUDI KASUS APLIKASI OGAN LOPIAN DINAS KOMUNIKASI DAN INFORMATIKA DI KABUPATEN PURWAKARTA. JURNAL POLITIKOM INDONESIANA, 3(1), 66-77.

Boes, K., Buhalis, D., \& Inversini, A. (2016). Smart tourism destinations: Ecosystems for tourism destination competitiveness. International Journal of Tourism Cities, 2(2), 108-124. https://doi.org/10.1108/IJTC-12-20150032

Buhalis, D. (2000). Marketing the competitive destination of the future. Tourism Management, 21(1), 97-116. https://doi.org/10.1016/S02615177(99)00095-3

Buhalis, D., \& Amaranggana, A. (2013). Smart Tourism Destinations. In Z. Xiang \& I. Tussyadiah (Eds.), Information and Communication Technologies in Tourism 2014 (pp. 553-564). Springer International Publishing. https://doi.org/10.1007/978-3-319-03973-2_40

Buhalis, D., \& Amaranggana, A. (2015). Smart Tourism Destinations Enhancing Tourism Experience Through Personalisation of Services. In I. Tussyadiah \& A. Inversini (Eds.), Information and Communication Technologies in Tourism 2015 (pp. 377-389). Springer International Publishing. https://doi.org/10.1007/978-3-319-14343-9_28

Divinagracia, L. A., Divinagracia, M. R. G., \& Divinagracia, D. G. (2012). Digital Media-Induced Tourism: The Case of Nature-based Tourism (NBT) at East Java, Indonesia. Procedia - Social and Behavioral Sciences, 57, 8594. https://doi.org/10.1016/j.sbspro.2012.09.1161

Divya, K. (2016). Study and reviews of smart city based tourism mobile app. International Journal of Computer Trends and Technology (IJCTT), 35(5), 226-230.

Gretzel, U. (2011). Intelligent systems in tourism. Annals of Tourism Research, 38(3), 757-779. https://doi.org/10.1016/j.annals.2011.04.014

Gretzel, U., Sigala, M., Xiang, Z., \& Koo, C. (2015). Smart tourism: Foundations and developments. Electronic Markets, 25(3), 179-188. https://doi.org/10.1007/s12525-015-0196-8

Gustini, Y., Sanusi, I., \& Muchtar, K. (2018). Pemerintah dalam Membentuk Citra Purwakarta Melalui Kearifan Lokal. Humas: Jurnal Ilmu Hubungan Masyarakat, 3(4), 97-115. 
Koo, C., Shin, S., Kim, K., Kim, C., \& Chung, N. (2013). Smart Tourism of the Korea: A Case Study. Smart, Open, and Social Information Systems, 138. http://aisel.aisnet.org/pacis2013/138

Lee, C.-F., \& Huang, H.-I. (2014). The Attractiveness of Taiwan as a Bicycle Tourism Destination: A Supply-Side Approach. Asia Pacific Journal of Tourism Research, 19(3), 273-299. https://doi.org/10.1080/10941665.2012.739190

Naibaho, W., \& Yusrizal, F. (2017). Efektivitas Website Dinas Pariwisata dan Kebudayaan Provinsi Jawa Barat sebagai Media Informasi Bagi Wisatawan. Jurnal Online Mahasiswa Fakultas Ilmu Sosial Dan Ilmu Politik Politik Universitas Riau, 4(2).

Neuhofer, B., Buhalis, D., \& Ladkin, A. (2012). Conceptualising technology enhanced destination experiences. Journal of Destination Marketing \& Management, 1(1-2), 36-46. https://doi.org/10.1016/j.jdmm.2012.08.001

Novianti, E., Nugraha, A. R., Komala, K., \& Komariah. (2019). Tourism Communication 4.0 in Purwakarta Regency. Sores.

Nurfalah, F., \& Wihayati, W. (2016). Peranan Media Promosi melalui Website yang Dilakukan Dinas Pariwisata dan Kebudayaan Jawa Barat dalam Menumbuhkan Minat Berwisata di Cirebon. Jurnal Signal Unswagati.

Panuju, R., \& Narena, I. (2019). Komunikasi Organisasi Bidang Reservasi Hotel. Jurnal Komunikasi, 11(1), 30-41.

Rencana Induk Pembangunan Kepariwisataan Provinsi Jawa Barat, 15 (2015).

Rachmayanti, M., \& Nofharina, N. (2018). Analisis Strategi Promosi Dalam Pengembangan Pariwisata (Studi Kasus Pada Pariwisata Kabupaten Purwakarta). Jurnal Komunikasi Dan Media, 2(2), 1-17.

Setyanto, Y., \& Winduwati, S. (2017). Diseminasi Informasi Terkait Pariwisata Berwawasan Lingkungan dan Budaya Guna Meningkatkan Daya Tarik Wisatawan (Studi pada Dinas Pariwisata Provinsi Nusa Tenggara Barat). Jurnal Komunikasi, 9(2), 164-175.

Tunggala, S., \& Saadjad, K. A. (2019). Strategi Komunikasi pada Dinas Kebudayaan dan Pariwisata dalam Mempromosikan Objek Wisata Kabupaten Banggai. Jurnal Komunikasi, 11(2), 197. https://doi.org/10.24912/jk.v11i2.2714

Tunjungsari, H. K., Selamat, F., \& Chairy, C. (2019). Pengukuran Destination Awareness Wisatawan Domestik pada Candi Muaro Jambi. Jurnal Komunikasi, 11(2), 233. https://doi.org/10.24912/jk.v11i2.5796

Wang, D., Li, X. (Robert), \& Li, Y. (2013). China's "smart tourism destination" initiative: A taste of the service-dominant logic. Journal of Destination Marketing \& Management, 2(2), 59-61. https://doi.org/10.1016/j.jdmm.2013.05.004

Wulung, S. R. P. (2018). SPATIAL MODEL ANALYSIS OF BANDUNG BASIN GEOTOURISM DESTINATION [Bandung Institute of Technology]. https://digilib.itb.ac.id/gdl.php?mod=browse\&op=read\&id=jbptitbpp-gdlshandraram-28074 
Evi Novianti, Shandra Rama Panji Wulung: Implementasi Komunikasi Daring dalam Menunjang Jawa Barat sebagai Destinasi Pariwisata Cerdas

Xiang, Z., \& Gretzel, U. (2010). Role of social media in online travel information search.

Tourism

Management, $31(2)$

179-188. https://doi.org/10.1016/j.tourman.2009.02.016 